\title{
Rare case of gastric perforation with malrotation and volvulus: A case report
}

\author{
Pathak M. ${ }^{1}$, Suchiang B. ${ }^{2}$, Narula $\mathrm{Dm}^{3}$ \\ ${ }^{1}$ Dr. Manish Pathak, Assistant Professor, Paediatric Surgery, ${ }^{2}$ Dr. Biangchwadaka Suchiang, Resident, General Surgery \\ Department, ${ }^{3}$ Dr. Dipanshu Narula, Resident, General Surgery Department; all authors are affiliated with R.N.T Medical \\ College, Near Collectorate, Hospital Rd, Court Chouraha, Udaipur, Rajasthan 313001, India
}

Address for correspondence: Dr. Biangchwadaka Suchiang, Email: dbbcc17@gmail.com

\begin{abstract}
Gastric perforation in neonate has always been a catastrophe associated with high morbidity. The high mortality rate reflects to a certain extent the precariousness of the neonatal period, but the process evolves so rapidly that prompt diagnosis is necessary if improved survival rates are to be achieved. It is a mysterious entity regarding its cause, but three mechanisms; spontaneous perforation, trauma and ischemia are acceptable reasons for neonatal gastric perforation. Nonetheless, we present you here a rare case of malrotation with mid gut volvulus which presented with apparently spontaneous gastric perforation $(1 \mathrm{x} 1 \mathrm{~cm})$. Primary repair of the perforation with derotation of the volvulus was done. We question the spontaneity of neonatal gastric perforation and urge the need to look for the contributing cause.
\end{abstract}

Keywords: Neonatal gastric Perforation (NBP); Spontaneous Gastric Perforation (SGP); Malrotation; Volvulus

\section{Introduction}

Neonatal gastric perforation is an unusual surgical emergency with a high mortality [1,2], the causes of which are not definite although literature has cited many theories regarding the pathogenesis of gastric perforation. Here we present a case of neonatal gastric perforation in our hospital in which malrotation and volvulus were the accompanying findings along with gastric perforation.

\section{Case Report}

A 7-day-old full term baby, weighing 2450g, was admitted with a history of abdominal distention, bleeding per rectum for 4 days. The patient had green colored vomitus and had not passed stool for 1 day. There was no complaint of any blood in vomitus.

The clinical exmination revealed a lethargic neonate with marked abdominal distention. Bowel sounds were absent. Abdominal X-ray revealed a large amount of free intraperitoneal gas giving a "saddle"or "football" sign due to massive pneumoperitoneum.

On exploration, there was malrotation with mid gut volvulus and gastric perforation $(1 \mathrm{x} 1 \mathrm{~cm})$ along the greater curvature, along with necrosis of the sero muscular area at the site of perforation. Primary repair of the perforation with derotation of the volvulus was done and the baby was shifted to neonatal ICU with stable vitals.

Post operative period was uneventful until day 8 , when there was wound dehiscence which was repaired with tension suturing. Histopathology of the margin of perforation area revealed nonspecific inflammation.

Manuscript received $10^{\text {th }}$ November 2016

Reviewed: $17^{\text {th }}$ November 2016

Author Corrected: $30^{\text {th }}$ November 2016

Accepted for Publication $13^{\text {th }}$ December 2016 


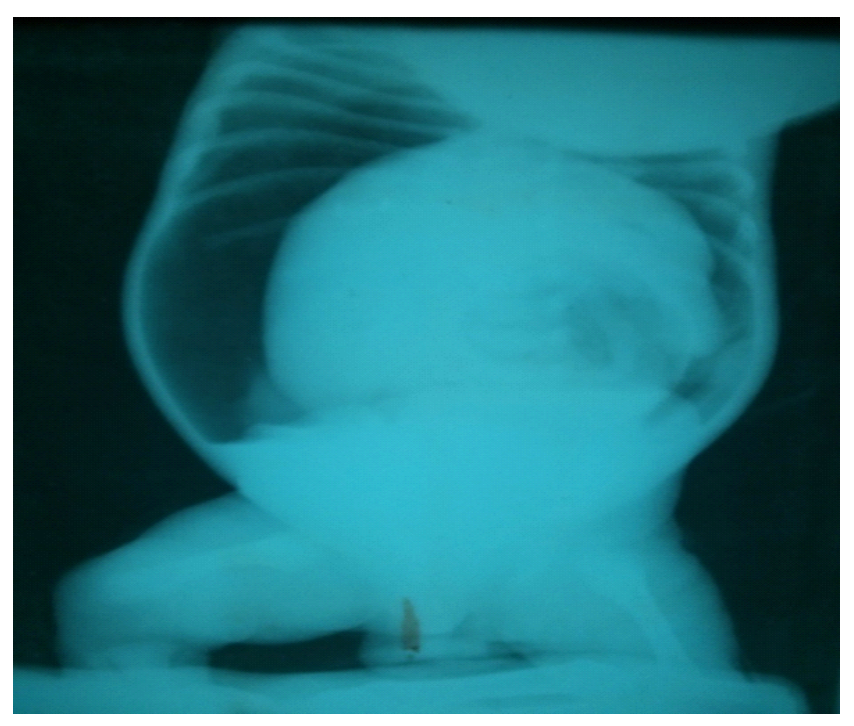

Figure-1: Pneumoperitoneum

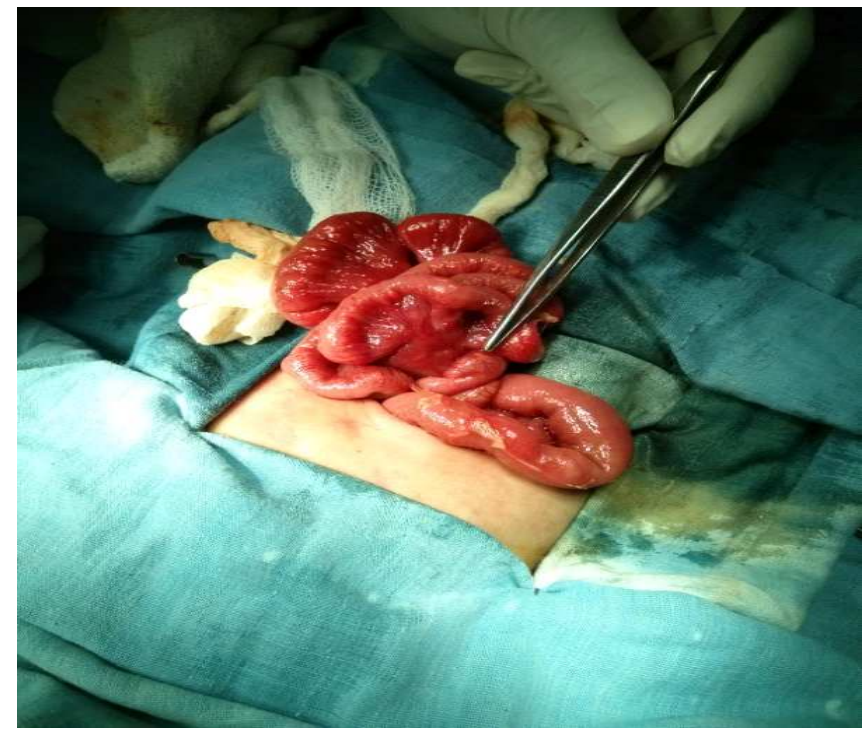

Figure-2: Malrotation with Volvolus

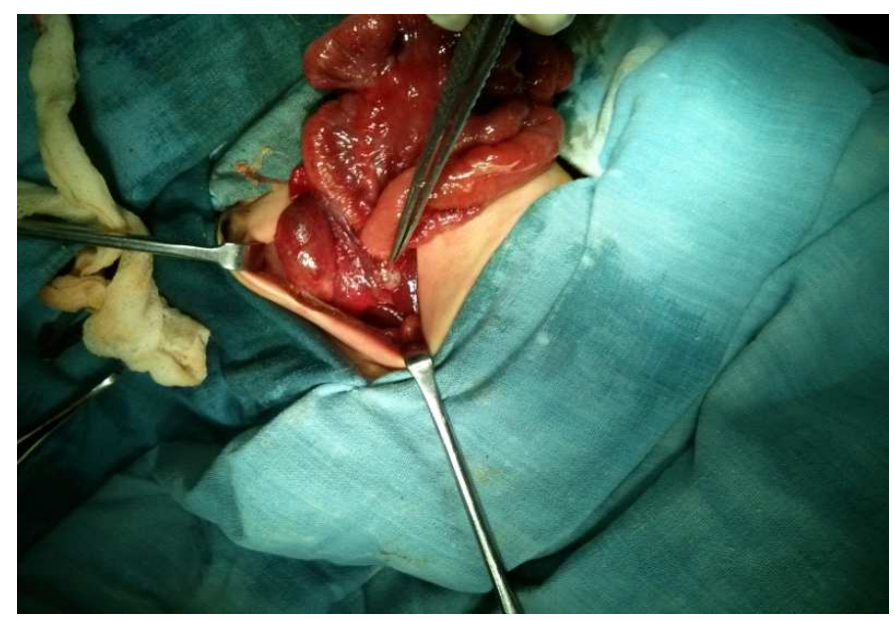

Figure-3: Gastric Perforation 


\section{Discussion}

Gastric perforation in the newborn infant was first described by Siebold in 1825[1]. Gastric perforation in neonate has always been a catastrophe associated with high morbidity [2]. The high mortality rate reflects to a certain extent the precariousness of the neonatal period, but the process evolves so rapidly that prompt diagnosis is necessary if improved survival rates are to be achieved.

Three mechanisms have been proposed for stomach perforation: traumatic, ischaemic, and spontaneous [3]. Most of the gastric perforations are due to iatrogenic trauma by vigorous nasogastric or orogastric tube placement $[3,4]$.

Historically gastric perforation has often been described as "spontaneous" [5], however it was found that prematurity and concomitant gastrointestinal lesions were associated with gastric perforation in the neonate and that few cases truly are spontaneous [6]. In normal weight infants, surgery is the treatment of choice, however, isolated gastric perforations in extremely low birth weight infant may be improved with percutaneous peritoneal drainage alone without need for primary surgical repair [7].

The most common radiographic finding of gastric perforation is pneumoperitoneum which was seen in our case but, finding which brings us to acknowledge this case was associated malrotation with mid gut volvulus.

In intestinal malrotation the small intestine has an unusually narrow base, and therefore the midgut is prone to volvulus (a twisting that can obstruct the mesenteric blood vessels and cause intestinal ischemia). Our case had normal birth weight. There was no history of any perinatal event leading to traumatic or ischemic gastric perforation.

There is a possibility that distal obstruction and stress due to intestinal malrotation with midgut volvulus may have predisposed gastric perforation. Midgut volvulus is a stress state and may lead to redistribution of blood flow with shunting away of blood from stomach with microvascular injury and loss of mucosal integrity $[5,6]$.

Midgut volvulus with ischemia of small bowel may also cause release of cytokines, tumour necrosis factor and platelet activating factor. This may lead to vasoconstriction, microvascular thrombosis, and ischemia of stomach causing gastric perforation.
Such a rare case of complex finding of gastric perforation associated with malrotation and midgut

volvulus has neither been documented in the literature so far nor they been etiologically interrelated. The authors believe that the so called spontaneous gastric perforation may not be spontaneous and a contributing cause should be looked for in such cases.

\section{Conclusion}

Our case of gastric perforation with malrotation and volvulus queries the spontaneity of the gastric perforation. The authors suggest that when gastric perforation occurs in neonates, a contributing cause should be sought.

Funding: Nil, Conflict of interest: None initiated Permission from IRB: Yes

\section{References}

1. Durham EC, Goldenstein RM. Rupture of the stomach in newborn infants. J Pediatr 1934;4:44. Cited Siebold: Heber Geschwurbildungen des Gastro Duodenal-Tractus in Kindesalter. Ergebn. inn.Med.u.Kinderh,1919;16:302.

2. Bayatpour M, Bernard L, McCune F, Bariel W. Spontaneous gastric rupture in the newborn. Am J Surg 1979; 137: 267-9.

3. Grosfield JL, Molinari F, Chaet $M$ et al. Gastrointestinal perforation and peritonitis in infants and children: experience with 179 cases over ten years. Surgery.1996 Oct;120(4):650-5; discussion 655-6.

4. Kieswetter W.B. Spontaneous rupture of the stomach in the newborn. Am J Dis Child 1956; 91:162-7.

5. Terui K, Iwai J, Yamada S, Takenouchi A, Nakata M, Komatsu S, Yoshida H. Etiology of neonatal gastric perforation: a review of 20 years' experience. Pediatr Surg Int. 2012 Jan;28(1):9-14. doi: 10.1007/s00383011-3003-4.

6. Leone RJ Jr, et al. Spontaneous neonatal gastric perforation: is it really spontaneous?. J Pediatr Surg. $2000 \mathrm{Jul} ; 35(7): 1066-9$.

7. Aydin M, Zenciroglu A, Hakan N, Erdogan D, Okumus N, Ipek MS. Gastric perforation in an 
extremely lowbirth weight infant recovered with Jul-Aug;53(4):467-70. percutaneous peritoneal drainage. Turk J Pediatr. 2011

\section{How to cite this article?}

Pathak M., Suchiang B., Narula Dm. Rare case of gastric perforation with malrotation and volvulus: A case report. Int J Med Res Rev 2016;4(11):1989-1992.doi:10.17511/ijmrr. 2016.i11.16. 